\title{
Serial Measurement of Superior Vena Cava Flow in Evaluation of the Clinical Severity of Pial Arteriovenous Fistula in an Infant
}

\author{
Mako Ago, MD ${ }^{1,2}$ Kenichi Masumoto, $\mathrm{MD}^{2}$ Atsushi Uchiyama, MD, PhD ${ }^{2}$ Yasuo Aihara, MD, $\mathrm{PhD}^{3}$ \\ Yoshikazu Okada, MD, $\mathrm{PhD}^{3}$ Satoshi Kusuda, MD, PhD ${ }^{2}$ \\ ${ }^{1}$ Department of Pediatrics, Faculty of Medicine, Shimane University, \\ Izumo-shi, Shimane, Japan \\ 2 Department of Neonatology, Maternal and Perinatal Center, Tokyo \\ Women's Medical University, Tokyo, Japan \\ ${ }^{3}$ Department of Neurosurgery, Neurological Institute, Tokyo \\ Women's Medical University, Tokyo, Japan \\ Address for correspondence Mako Ago, MD, Department of \\ Pediatrics, Faculty of Medicine, Shimane University, 89-1 Enya-cho, \\ Izumo-shi, 693-8501, Shimane, Japan \\ (e-mail: ago-mako@med.shimane-u.ac.jp).

\begin{abstract}
Keywords

- pial arteriovenous fistula

- superior vena cava flow

- high-output cardiac failure

- infant

Background Pial arteriovenous fistula (AVF) is composed of one or more direct arterial feeding vessels with a single draining vein without nidus. A patient with the disease with high-flow AV shunting in the neonatal period not only suffers from high-output cardiac failure but also shows secondary neurological sequelae. In vein of Galen aneurysmal malformation, superior vena cava (SVC) flow measurements provide useful prognostic information.

Case Presentation We measured serial SVC flow in a male infant with pial AVF. The term infant presented with tachypnea, a heart murmur, and a cranial bruit after birth, and cranial magnetic resonance imaging and computed tomographic angiography revealed a pial AVF on the left sylvian fissure. SVC flow was at the upper normal limit at presentation. After 1 month, SVC flow gradually increased up to fourfold. Surgical resection of the pial AVF was performed and diagnosed as pial AVF on day 62 . The SVC flow immediately decreased thereafter.

Conclusion SVC flow reflects the shunt volume and may be a useful parameter for evaluating the optimal timing and effectiveness of intervention in pial AVF.
\end{abstract}

Pial arteriovenous fistula (AVF) is a rare intracranial vascular malformation in which one or more arteries connect directly to a vein without an intervening nidus, often accompanied by large venous pouches. In neonates presenting with high-output cardiac failure due to high-flow AV shunting, prognosis is worse with conservative management. ${ }^{1}$ Therefore, rapid control of the lesion is attempted in the absence of brain damage. ${ }^{2}$

Vein of Galen aneurysmal malformation (VGAM) is also an intracranial AV malformation with high-output cardiac failure due to high-flow AV shunting. ${ }^{2,3}$ It is associated with multiorgan failure in some patients. In neonates who have multiorgan failure or brain damage, even if an emergency procedure is properly performed, the neurological outcome can be disastrous. Heuchan and Bhattacharyha measured superior vena cava (SVC) flow in VGAM, and showed that the outcome was poor in patients with a flow $>400 \mathrm{~mL} / \mathrm{kg} / \mathrm{min}^{4}$

Herein, we report the case of an infant with pial AVF in which the therapeutic strategy was evaluated by measuring the serial SVC flow.

\section{Case Presentation}

A male neonate weighing 3,238 g was born at $40^{4 / 7}$ weeks of gestation. Apgar scores were 9 and 10 at 1 and 5 minutes, received

June 1, 2016

accepted after revision

November 3, 2016
DOI http://dx.doi.org/

$10.1055 / \mathrm{s}-0036-1597572$. ISSN 2157-6998.
Copyright $\odot 2017$ by Thieme Medical Publishers, Inc., 333 Seventh Avenue, New York, NY 10001, USA. Tel: +1(212) 584-4662.

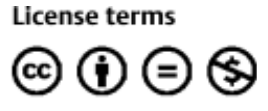


respectively. Tachypnea and a heart murmur appeared 2 hours after birth. The systolic heart murmur of Levine II/VI was heard on the fourth left sternal border. Chest radiography revealed a cardiothoracic ratio (CTR) of $68 \%$. Echocardiography showed tricuspid regurgitation without structural anomaly. The flow velocity was $4.3 \mathrm{~m} / \mathrm{s}$, consistent with estimated elevated right ventricular pressure. Bidirectional flow was detected in both the patent ductus arteriosus and patent foramen ovale. At 5 days of age, retrograde diastolic flow was seen in the distal transverse arch and the descending aorta. Cranial bruit on the anterior fontanel was audible. A dilated left middle cerebral artery and abnormal blood flow were detected just under the left front-temporal bone on cranial ultrasonography (-Fig. 1A). The cranial magnetic resonance imaging and magnetic resonance angiography examinations showed single AV malformation on the left sylvian fissure ( - Fig. 1B, C), but no focal steal ischemic change was observed in the left cerebral hemisphere. The patient was treated conservatively with diuretics. The SVC flow, proposed by Kluckow and Evans, ${ }^{5}$ of the infant was $117 \mathrm{~mL} / \mathrm{kg} / \mathrm{min}$, approximately the upper normal limit in term infants (-Fig. 2). After 1 month, tachypnea and tricuspid regurgitation were reduced, but weight gain was still poor. Conversely, the SVC flow increased to $277 \mathrm{~mL} / \mathrm{kg} / \mathrm{min}$. Even though his weight gain temporarily slightly improved during the preoperative period, poor oral feeding continued. Therefore, nasogastric tube feeding was needed for the patient to gain body weight. We substituted a four-dimensional computed tomographic angiography for catheter cerebral angiography because it is a less invasive procedure. Results of the examination showed that a lesion was located in the superficial area of the brain and was suspected to have a pial AVF (-Fig. 3 ). Based on the results, we believed that open surgery was safer than endovascular embolization due to a difficult approach to the region because the access, such as umbilical vessels, was already closed. ${ }^{6}$ The SVC flow increased further to $413 \mathrm{~mL} / \mathrm{kg} /$ min just before the operation (-Fig. 2). Therefore, a surgical intervention was planned to reduce the shunt flow. He underwent surgical resection at 62 days of age. A pial AVF was confirmed, and the dilated abnormal AV system was resected. The SVC flow decreased to $136 \mathrm{~mL} / \mathrm{kg} / \mathrm{min}$ immediately after the operation and the cranial bruit disappeared. The poor oral feeding also improved, and the nasogastric tube feeding was discontinued. Cardiomegaly subsided gradually and the CTR became 57\%. The patient was discharged approximately 2 weeks after the operation without neurological sequelae. His growth and development continue to be normal at 6 months of age.
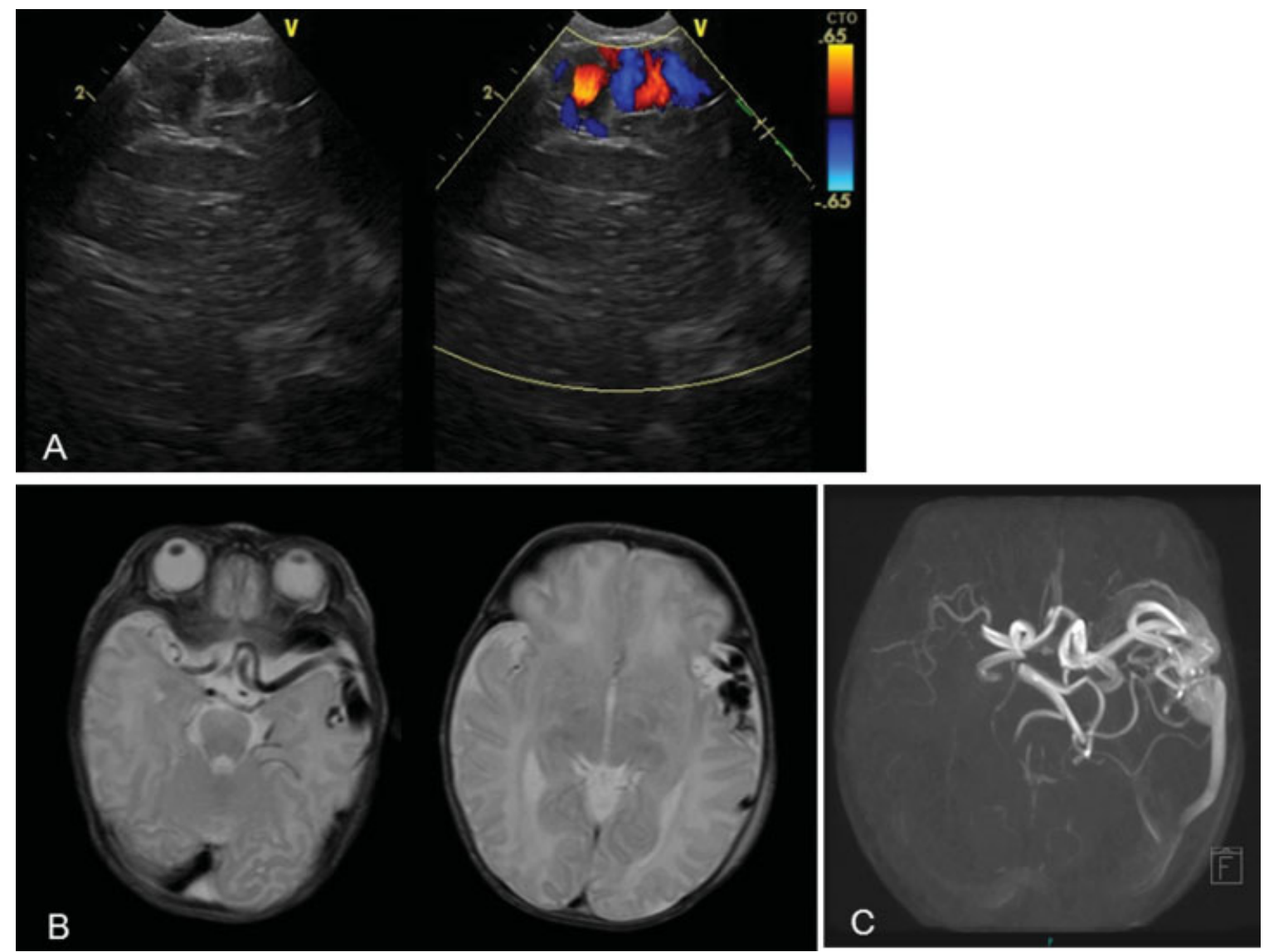

Fig. 1 Cranial ultrasonography, MRI, and MRA of the patient with pial AVF. (A) Cranial ultrasonography (left temporal lobe): Abnormal blood flow is visible just under the left temporal bone. (B) Cranial MRI (T2-weighted image): A pial AVF at the left sylvian fissure with dilated left middle cerebral artery and venous pouch (flow-void area) is visible on the left temporal lobe. (C) Cranial MRA: An AVF supplied by a single branch of the left middle cerebral artery with an enlarged venous pouch draining to the left sylvian fissure is visible on the left temporal lobe. AVF, arteriovenous fistula; MRA, magnetic resonance angiography; MRI, magnetic resonance imaging. 


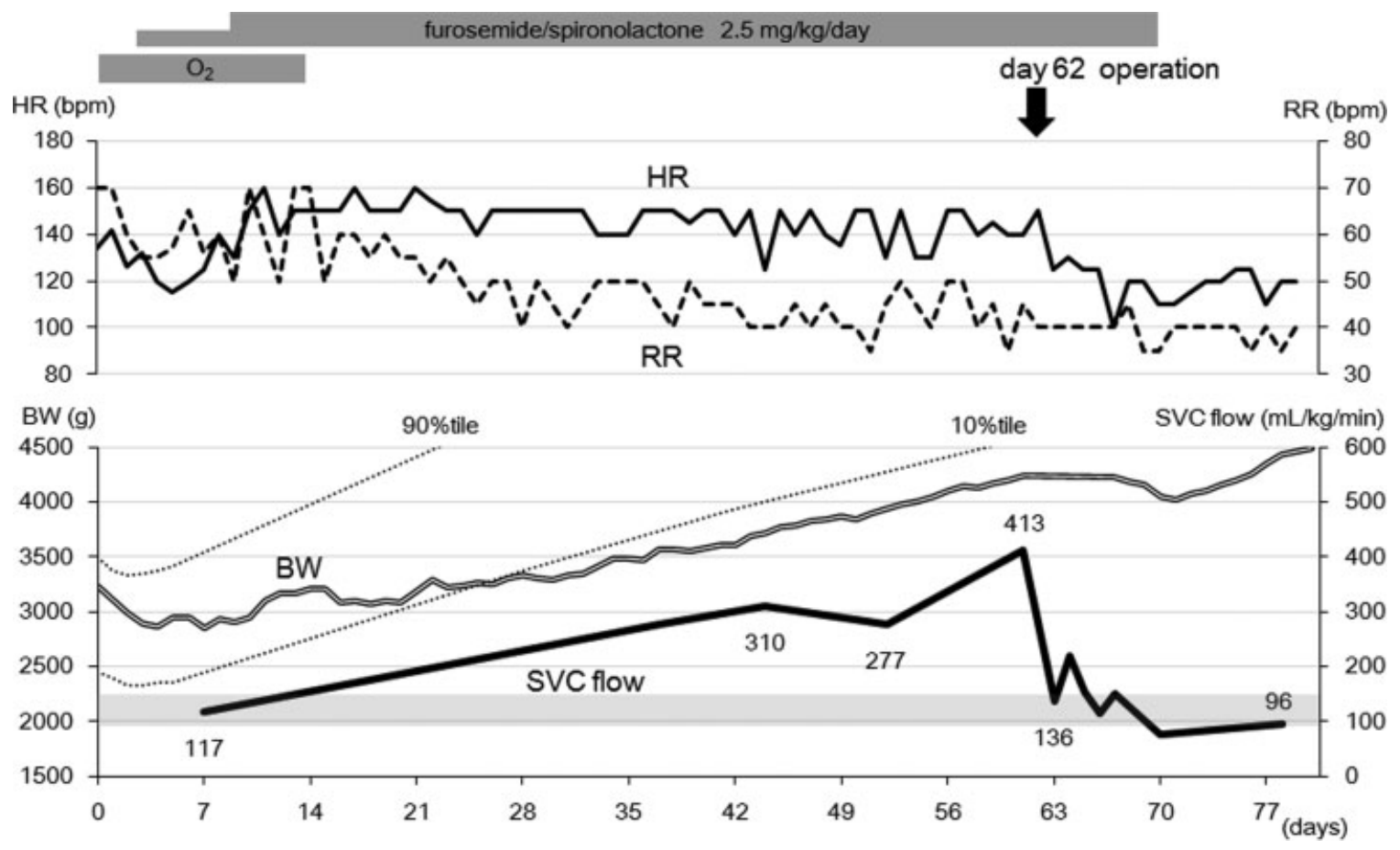

Fig. 2 Clinical course of the patient. Initially, the patient was treated conservatively with diuretics. After 1 month, tachypnea had subsided, but weight gain was still poor. SVC flow of the patient increased to $413 \mathrm{~mL} / \mathrm{kg} / \mathrm{min}$ just before the operation at 62 days of age. After the operation, the SVC flow decreased to $136 \mathrm{~mL} / \mathrm{kg} / \mathrm{min}$ immediately. Thereafter, weight gain improved. The shaded zone shows the normal range of SVC flow, which is from 55 to $111 \mathrm{~mL} / \mathrm{kg} / \mathrm{min} .{ }^{5} \mathrm{BW}$, body weight; HR, heart rate; RR, respiratory rate; SVC, superior vena cava.

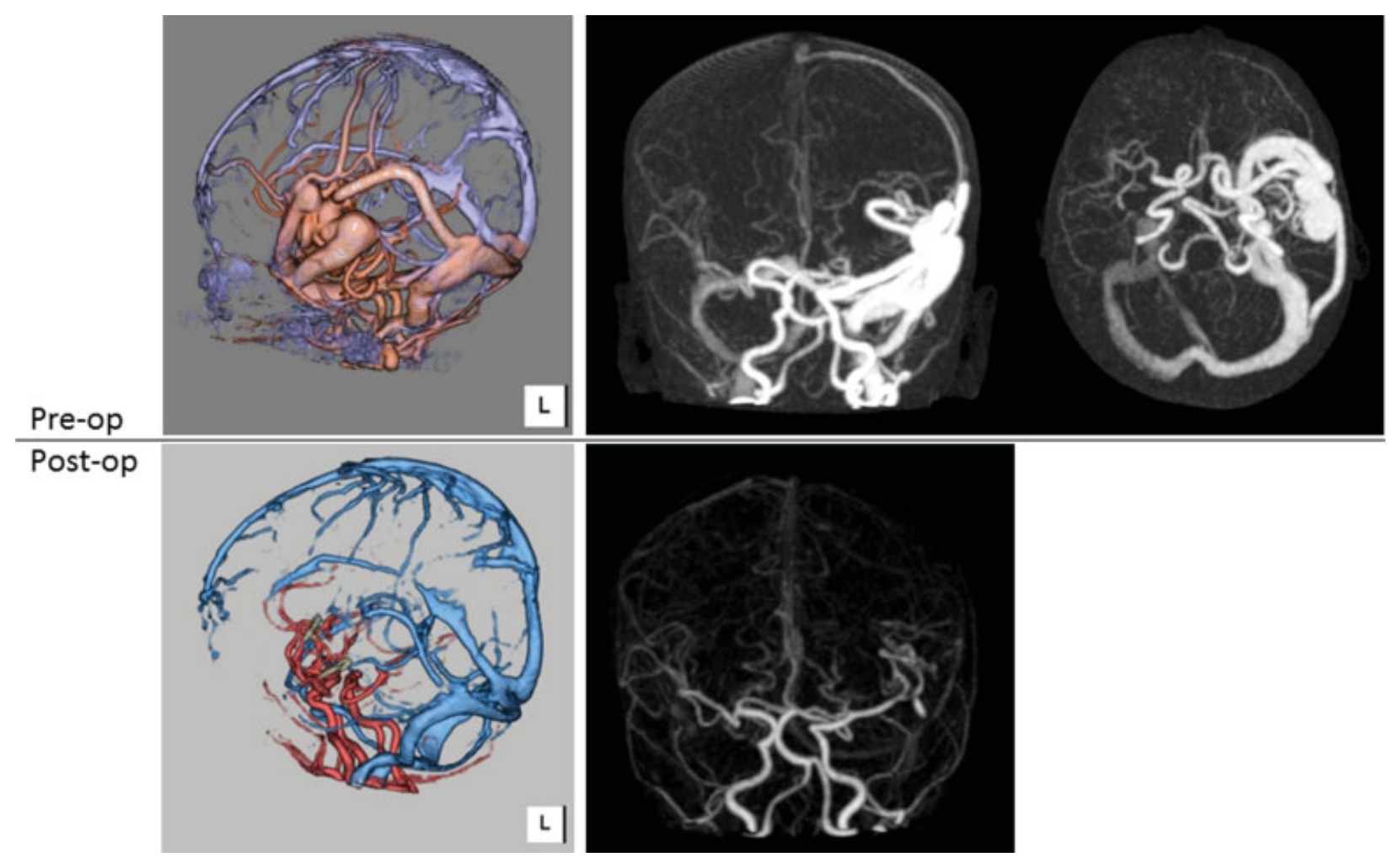

Fig. 3 Cranial four-dimensional computed tomographic angiography in the patient with pial AVF. Upper part: preoperative images. A pial AVF with a dilated left middle cerebral artery and venous pouch is visible. The venous pouch and drainage veins are already enhanced on arterial phase. Lower part: postoperative images. There is no arteriovenous malformation or abnormal blood perfusion. AVF, arteriovenous fistula. 


\section{Discussion}

The clinical course of this patient suggests the following two important clinical issues.

First, in a patient with pial AVF, SVC flow may markedly increase after birth. We measured SVC flow as is done with VGAM because the intracranial vascular malformation with high-flow shunting was accompanied by high-output cardiac failure. The SVC flow was approximately the upper normal limit initially but exceeded $400 \mathrm{~mL} / \mathrm{kg} / \mathrm{min}$ after 2 months. We speculate that the increase in the SVC flow reflected the change of the AV shunt volume because the flow decreased dramatically after the operation. Holden et $\mathrm{al}^{7}$ and Patton and Fouron ${ }^{8}$ stated that cardiac failure is asymptomatic in utero despite a severe cardiac burden because the fistula competes with the low resistance circulation of the placenta. After conversion to extrauterine circulation, the fistula abruptly increases its flow, and volume overload is equally borne by the right and left ventricles in series. Therefore, cardiac failure symptoms worsen drastically after birth. Patton and Fouron ${ }^{8}$ and Musewe et $\mathrm{al}^{9}$ showed echocardiography findings of an enlarged SVC and right heart and turbulent Doppler flow in the SVC. Lasjaunias et al reported that cardiac failure in VGAM generally worsens during the first 3 days of life; however, the degree of worsening is independent of the characteristics of the shunt. ${ }^{3}$ The steady increase in the SVC flow in our patient may be one of the various courses in pial AVF.

Second, SVC flow may be a useful parameter to evaluate the optimal timing and effectiveness of intervention in pial AVF. Heuchan and Bhattacharyha reported that the patients with SVC flow $>400 \mathrm{~mL} / \mathrm{kg} / \mathrm{min}$ at presentation had poor outcomes. In our patient with pial AVF, tachypnea subsided, and weight gain also improved by medical treatment. However, poor oral feeding continued and SVC flow of the patient exceeded $400 \mathrm{~mL} / \mathrm{kg} / \mathrm{min}$ just before the operation. Furthermore, the SVC flow dramatically decreased after the operation and the oral feeding also improved. These results may suggest that SVC flow is a more helpful indicator for surgical intervention of pial AVF.

In conclusion, the increasing of SVC flow may reflect the shunt volume and is a useful parameter in the evaluation of the optimal timing and effectiveness of intervention in pial AVF. It is important to measure the flow repeatedly in intracranial AV malformation with high-output cardiac failure. Further data/cases are warranted to determine the optimal value of SVC flow for intervention in pial AVF.

\section{Acknowledgment}

We thank Cactus Communications Pvt. Ltd. for editing the medical English language of the article.

\section{References}

1 Hetts SW, Keenan K, Fullerton HJ, et al. Pediatric intracranial nongalenic pial arteriovenous fistulas: clinical features, angioarchitecture, and outcomes. AJNR Am J Neuroradiol 2012; 33(9):1710-1719

2 Toma AK, Davagnanam I, Ganesan V, Brew S. Cerebral arteriovenous shunts in children. Neuroimaging Clin N Am 2013;23(4): 757-770

3 Lasjaunias PL, Chng SM, Sachet M, Alvarez H, Rodesch G, GarciaMonaco R. The management of vein of Galen aneurysmal malformations. Neurosurgery 2006;59(5, suppl 3):S184-S194, discussion S3-S13

4 Heuchan AM, Bhattacharyha J. Superior vena cava flow and management of neonates with vein of Galen malformation. Arch Dis Child Fetal Neonatal Ed 2012;97(5):F344-F347

5 Kluckow M, Evans N. Superior vena cava flow in newborn infants: a novel marker of systemic blood flow. Arch Dis Child Fetal Neonatal Ed 2000;82(3):F182-F187

6 Komiyama M, Nishikawa M, Kitano S, et al. Transumbilical embolization of a congenital dural arteriovenous fistula at the torcular herophili in a neonate. Case report. J Neurosurg 1999;90(5): 964-969

7 Holden AM, Fyler DC, Shillito J Jr, Nadas AS. Congestive heart failure from intracranial arteriovenous fistula in infancy. Clinical and physiologic considerations in eight patients. Pediatrics 1972; 49(1):30-39

8 Patton DJ, Fouron JC. Cerebral arteriovenous malformation: prenatal and postnatal central blood flow dynamics. Pediatr Cardiol 1995;16(3):141-144

9 Musewe NN, Smallhorn JF, Burrows PE, Izukawa T, Freedom RM. Echocardiographic and Doppler evaluation of the aortic arch and brachiocephalic vessels in cerebral and systemic arteriovenous fistulas. J Am Coll Cardiol 1988;12(6):1529-1535 